\title{
Potential of forest melliferous resources of northwest Russia
}

\section{Introduction}

Viability and productivity of bee families largely depends on environmental conditions, and especially on feed availability and weather favorable for flights of bees. These days steadily growing technogenic pollution is becoming more and more dangerous for bees that cannot but affect physical condition of bees and quality of apiculture products.

Territory of Russia includes a great variety of natural and climatic zones. In this view there is a need in development of various technologies of maintenance and reproduction of bee families. Northwest Russia differs from other natural and climatic zones of Russia. This region has extensive food supply for bees. ${ }^{1-3}$ However unstable weather conditions make its use complicated. During spring-summer period frequent falls in temperature preventing proper functioning of bee families and in winter-interchange of thaws with cold snaps make wintering complicated. Therefore beekeeping of the region incurs heavy losses, and indoor wintering widely used in other regions (different types of apiary houses) is applied restrictedly.

Basing on the foregoing, development of technologies ensuring directed impact on development process of bee families during spring-summer period and their safety during wintering is relevant for Northwest Russia. To use feed availability of the region efficiently it is required to specify data on stock and condition of these resources.

\section{Subject and methods of research}

Subject of research is forest melliferous resources of Northwest Russia. The resources of forest and non-forest lands, both lands covered with vegetation and lands not covered with forests were evaluated. Honey plants were recorded by routes on discount area of $10 \mathrm{~m}^{2}$. On each land plot there were at least three routes each of which included at least 30 discount areas. Total number of discount areas complied with a record rate. In our researches a value equal to $2 \%$ of total area of the experiment facility was accepted as the record rate. ${ }^{4}$ In each discount area a detailed research of vegetation was held, in addition flowering phase of honey plants was recorded: early flowering, stable flowering, and end of flowering. Flowering plants were recorded from March to October. Moreover, honey and beebread plants were singled out (Rules of forest utilization for farming purposes..., 2011; Guidelines for record and evaluation of secondary forest resources ..., 2003). To show flowering dynamics of basic honey plants such indicator as a flowering curve was applied. The flowering curve is a diagram showing dependency of a number of efflorescing, flowering, and deflored species on time for the whole vegetation period (a number of species is taken into account by ten-day intervals).

Area of apiaries was taken as equal to 1260 ha basing on estimation of bee flight radius of about $2 \mathrm{~km}$. Volume of nectar available to bees was estimated at the rate of $50 \%$ of total volume of nectar generation by plants. Honey plants flowering till 10 June are referred to spring honey plants, those species flowering peak of which falls on the period of 10 June to 10 July are referred to early summer plants, and species flowering after 10 July were considered summer plants. ${ }^{2}$
Volume 2 Issue 6 - 2018

\author{
Griazkin, AV,' Samsonova ID,' Belyaeva NV,' \\ Belyaev VV, ${ }^{2}$ Gutal Marko, ${ }^{3}$ Feklistov PA ${ }^{2}$ \\ 'Doctor of Biological Sciences, Professor of the Department of \\ Forestry of the St. Petersburg State Technical University, Russia \\ ${ }^{2}$ Northern (Arctic) Federal University, Russia \\ ${ }^{3}$ University of East Sarajevo, Russia
}

Correspondence: Samsonova ID, Doctor of Biological Sciences, Professor of the Department of Forestry of the St. Petersburg State Technical University named after S.M. Kirov, Russia,Email lesavod@bk.ru

Received: June 12, 2018 | Published: December 17, 2018

\section{Results and discussion}

In the beginning of vegetation period basic honey plants of the region are hardy-shrub species (alder, avellan, willows). Then they are changed by stone fruit species, berry shrubs, and pomefruit trees. In early spring the following herbage plants blossom: coltsfoot, common lungwort, common dandelion. Further they are followed by shrub vegetation of forests and herbaceous vegetation of meadows, hay lands, and pastures, as well as weeds. In summer period essential nectar source of forest zone is rosebay. At the end of vegetation period in Northwest Russia the main honey plant is common heather.

The shortest flowering period of 9 to 23 days is peculiar for spring honey plants, and summer plants have the longest period of 24 to 54 days. The main autumn honey plant - common heather - is also characterized by long flowering period. Its flowering can last 26 to 40 days.

According to results of 12-year observations such species of plants as grey alder, black alder, and avellan (24-26 March) are referred to the earliest polliniferous plants breaking into blossom in the third tenday period of March. First nectar plants effloresce in the second tenday period of April starting from 14-16 day.

The main (basic) honey flow is ensured by honey plants growing on areas not covered with forests. Mainly they include clover, melilot, vetch, brown knapweed, creeping thistle, and rosebay. Flowering of these species falls on June to August (02.07-15.08). Flowering period of basic honey plants can change depending on weather conditions of a year. Difference in research years makes 5 to 8 days. It should be noted that on south slopes plant effloresce 5-7 days earlier than on northern slopes. This fact also extends period of their flowering.

In the region autumn honey flow is ensured mainly by heather, wild growing herbs of hay lands, pastures, and permanent legume grasses.

Under conditions of Northwest Russia flowering of plants from which bees procure pollen and nectar start from early spring and ends in late autumn. However opportunity to use them is limited by weather conditions unfavorable for flights. Therefore, essence of beekeeping technology is to ensure an optimal number of bee families during 
the whole annual cycle. It should be relatively small during period unfavorable for honey flow, and reach a maximum in period during which bees can use melliferous resources as intensively as possible.

Researches held by GSYaroshevich ${ }^{5}$ in 1999-2000 with respect to sugar content in nectar of honey plants showed high sugar productivity of some species of plants (birds-foot trefoil, brown knapweed, and Eastern galega). Studied species of clover turned out to be less productive. Next year (in 2000) sugar content in nectar of studied species was significantly lower as compared to the previous year. Difference of sugar content in nectar between the research years made $6.9-20.4 \%$ depending on a studies species. The greatest difference in the research years was observed for Eastern galega (20,4\%), different species of clover 15.5 to $18.4 \%$ (Figure 1). First of all, it is connected with a fact that weather conditions of vegetation period 2000 were unfavorable for generation of sugar in flowering due to high humidity and lower daily mean temperatures.

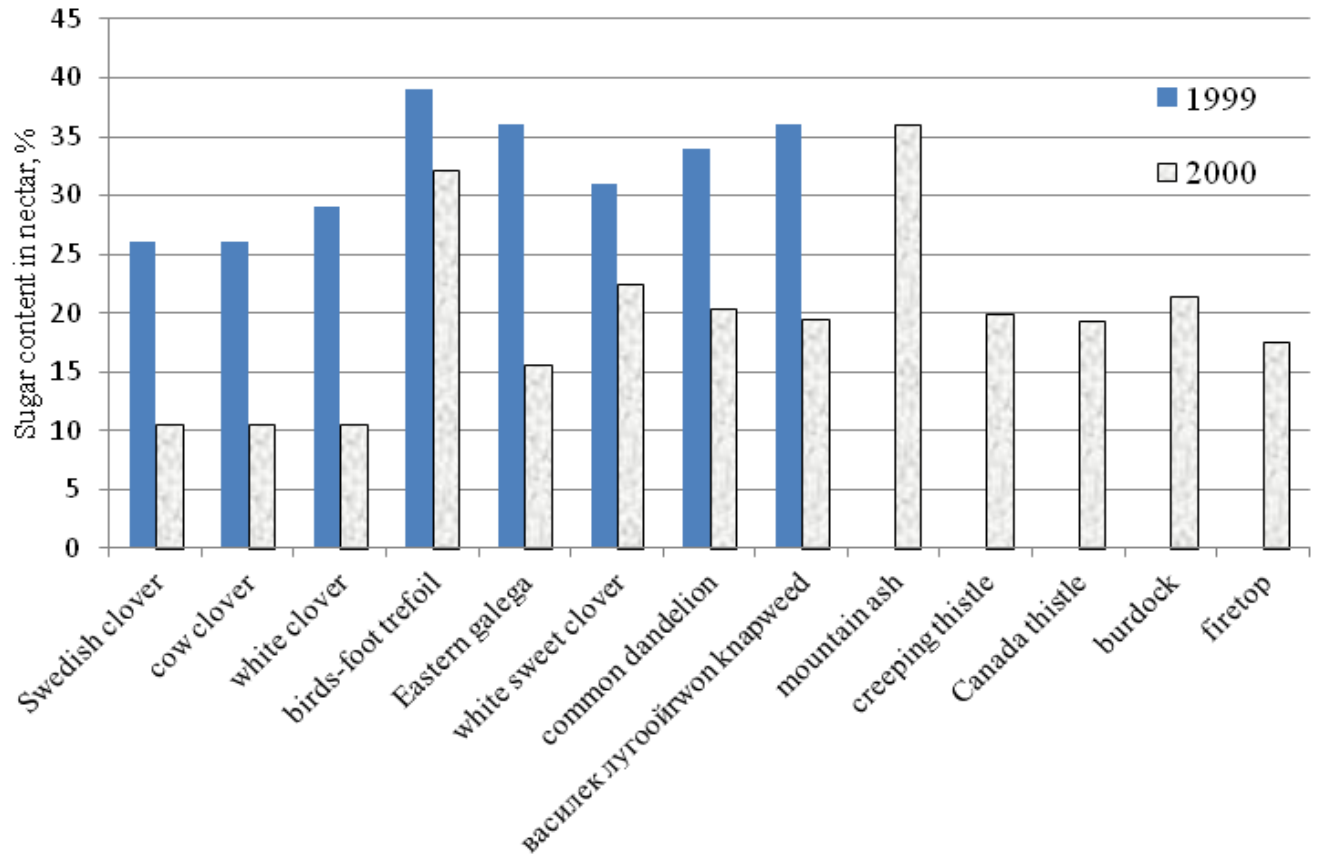

Figure I Sugar content in nectar of entomophilous plants in 1999-2000,\%.

Northwest Russia has favorable conditions to produce ecologicallyfriendly apiculture products. However beekeeping is under-developed here. Numerous honey and polliniferous plants are not almost used representing a huge reserve for beekeeping. Ecological conditions are favorable, especially in areas remote from settlements. All these facts allow to speak about good prospects of beekeeping development in the region and an opportunity to get valuable apiculture products.

Estimations of VV Soloviev ${ }^{6}$ show that early summer and especially summer honey flow is significantly by its volume to spring honey flow. Theoretically, it is spring when maximum honey flow must take place. But several reasons prevent from using spring honey flows. The most important are unfavorable weather conditions and insufficient readiness of bee families to honey flow. Utilization of spring honey flow is the main reserve of honey harvest. As practice shows, due to special preparation of families to spring honey flow can significantly increase harvest of spring honey.

In practice basic honey flow starts in June, lasts till early July and then rapidly ends up upon flowering of clover. Two species of clovercreeping trefoil and Swedish clover-are the main honey sources in this area.

Difficulty of using early summer and summer honey flows lies in a fact that peak of bee swarming occurs at the same period.

Under conditions of Northwest Russia the most productive areas are burned-out forests and cleanings in woods. Depending on a forest type total number of honey species can reach 28-45. It has been established that species composition of honey plants growing under forest canopy slightly depends on a forest type. According to observations made by scientists of the Forestry Department of Saint-Petersburg State Forest Technical University, ${ }^{7}$ in this case to a greater extend their occurrence is affected by canopy closure, lighting regime under the canopy, i.e. characteristics of the upper layer of forest community. The most shade-enduring species are referred to taiga short grassesshamrock (Oxalisacetosella L.), may lily (Maianthemumbifolium (L.) F.W.Schmidt), chickweed wintergreen (Trientaliseuropaea L.).

The most shade-enduring species of shrubs are February daphneDaphnemezereum L. and alder buckthorn (Frangulaalnus Mill.). Under conditions of European taiga the first early flowering species of shrubs is February daphne.

To evaluate quality of bee pasturages and estimation of their use duration during a season it was made up a flowering diagram, essence of which is in distribution of a total number of honey plants flowering on different stages for the whole honey flow season by tenday intervals. Duration of flowering, times of start and end of honey plant flowering significantly vary (Figure 2).

As seen from the Table 1, the largest amount of flowering species growing in burned-out forests of Northwest Russia falls on July. In this period simultaneously up to 27 species of honey plants growing 
in burned-out forest can be in active flowering phase. Even under conditions of the middle taiga flowering of some honey plants starts in the third ten-day period of April - snowdrop anemone (Anemone sylvestris L.), common lungwort (Pulmonaria officinalis L.), and for some species end of flowering falls on the second-third ten-day periods of October - European goldenrod (Solidagovirgaurea L.), creeping trefoil (Trifolium repens L.), and heal all (Prunella vulgaris L.). Efflorescence of most honey plants falls on the second ten-day period of May. In the third ten-day period of May a number of species in efflorescence phase and a number of species in abundant flowering phase reach 19 in total.

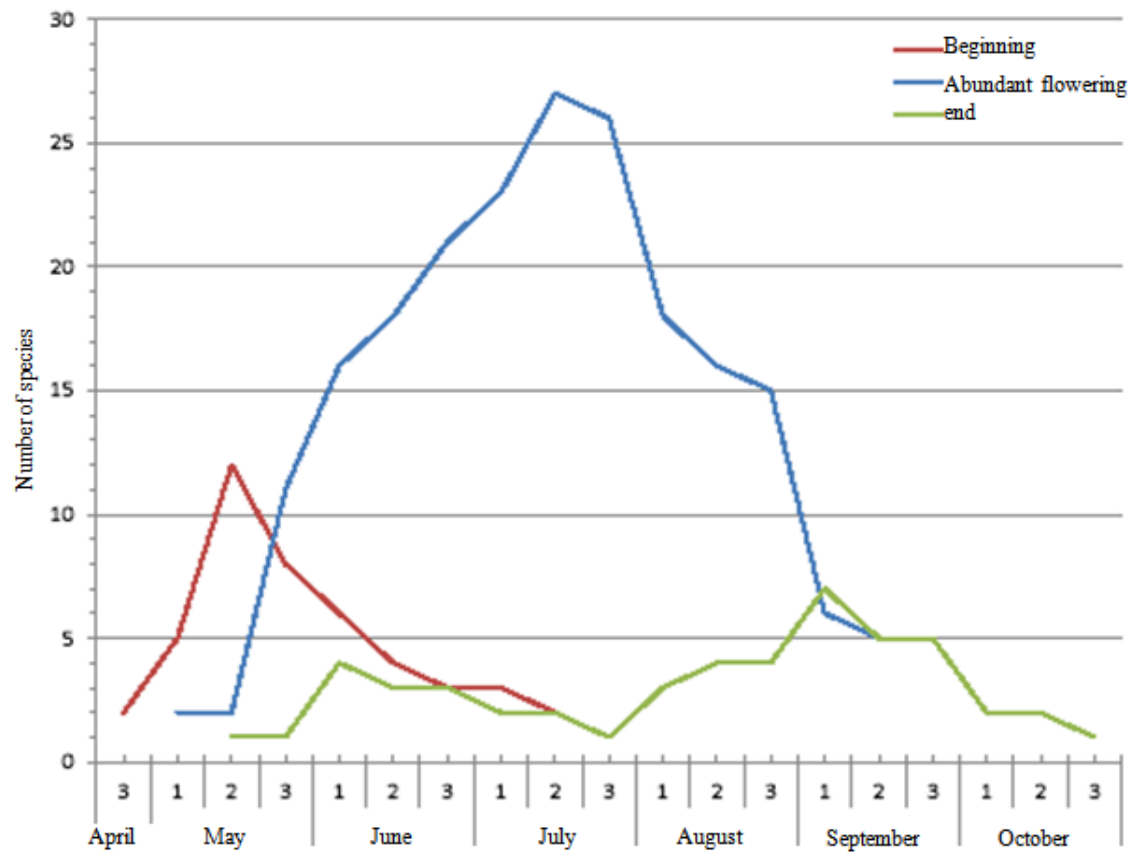

Figure 2 Flowering of honey plants in burned-out forests under conditions of Northwest Russia.

Table I List of honey plants by land categories of forest resources

\begin{tabular}{llll}
\hline \multirow{2}{*}{ Species } & \multicolumn{2}{c}{ Category of forest lands } & \\
& burned-out forest & clearing in woods & timber stand \\
\hline Cirsiumheterophyllum(L.) Hill. & + & + & + \\
Vaccíniumvítis-idaéaL. & + & - & + \\
GlechomahederaceaL. & + & - & + \\
LysimachiavulgarisL. & + & + & - \\
Callunavulgaris(L.)Hull. & + & - & + \\
VeronicaofficinalisL. & + & + & + \\
VeronicachamaedrysL. & + & + & + \\
Anemone sylvestrisL. & + & + & + \\
Geranium robertianumL. & - & + & - \\
ViciasepiumL. & + & + & - \\
ViciacraccaL. & + & + & - \\
GeumurbanumL. & + & + & + \\
GeumrivaleL. & + & + & - \\
AngélicasylveśtrisL. & + & + & + \\
StellariaholosteaL. & + & + & + \\
Stellariamedia (L.) Cyr. & + & + & - \\
HypericumperforatumL. & + & + & - \\
FragariavescaL. & + & + & + \\
SolidagovirgaureaL. & + & + & \\
\hline & & + &
\end{tabular}


Table Continued...

\begin{tabular}{|c|c|c|c|}
\hline \multirow{2}{*}{ Species } & \multicolumn{3}{|c|}{ Category of forest lands } \\
\hline & burned-out forest & clearing in woods & timber stand \\
\hline CalthapalustrisL. & - & + & - \\
\hline ScirpussylvaticusL. & + & + & + \\
\hline TrifoliumrepensL. & + & + & - \\
\hline TrifoliummediumL. & + & + & - \\
\hline TrifoliumpratenseL. & + & + & - \\
\hline RubussaxatilisL. & + & - & + \\
\hline UrtícadioicaL. & + & + & + \\
\hline TrolliuseuropaeusL. & + & + & - \\
\hline Anthriscussylvestris (L.) Hoffm. & + & + & + \\
\hline ConvallariamajalisL. & + & - & + \\
\hline Potentillaerecta(L.)Raeusch. & + & + & - \\
\hline Platantherabifolia(L.)Rich. & - & + & - \\
\hline MajanthemumBifolium (L.) F.W.Schmidt & + & - & + \\
\hline RubusidaeusL. & + & - & + \\
\hline AlchemillavulgarisL. & - & + & - \\
\hline MelampyrumnemorosumL. & + & + & + \\
\hline PulmonariaofficinalisL. & - & + & + \\
\hline MyosotisnemorosaBess. & + & + & + \\
\hline TaraxacumofficinaleWebb. & + & + & - \\
\hline CarexmediaR.Br. & + & + & + \\
\hline CarexmelanostachyaM. Bieb. Ex Willd. & + & + & + \\
\hline CarexminutaFranch. & + & + & - \\
\hline SonchusarvensisL. & + & + & - \\
\hline MatricariadiscoideaDC. & + & + & - \\
\hline TrientaliseuropaeaL. & + & - & + \\
\hline Crepispaludosa(L.)Moench & - & + & + \\
\hline AegopodiumpodagrariaL. & + & + & + \\
\hline FilipendulaulmariaL. & + & + & + \\
\hline AchilleamillefoliumL. & + & + & - \\
\hline VaccíniummyrtíllusL. & + & - & + \\
\hline Prunella vulgaris $\mathrm{L}$. & + & + & - \\
\hline ChelidoniummajusL. & + & + & - \\
\hline RumexacetosaL. & + & + & - \\
\hline RumexconfertusWilld. & + & + & - \\
\hline RumexacetosellaL. & + & + & - \\
\hline OrchismaculataL) & - & + & - \\
\hline
\end{tabular}

By the first half of July all honey species effloresce. On the other side by the second ten-day period of May the flowering phase of some honey species is already completed. Most early flowering species, mainly ephemerals, complete the flowering phase by the first tenday period of June, and under conditions of Leningrad region most "summer" and late-flowering species complete their flowering phase in the first ten-day period of September.

Research results showed that flowering terms of one and the vary species significantly vary depending on conditions of growing area. In open areas flowering of most plants, including honey plants, starts earlier than those growing under forest canopy by 1-2 ten-day periods. On the other hand, flowering period of many studied species growing under forest canopy is longer than those growing in open area by 8-14 days.

List of basic species growing in forest resources of Northwest Russia by land categories is given in the Table 1 . 
Under conditions of Northwest Russia melliferous capacity of pasturages averages about $25-30 \mathrm{~kg} / \mathrm{ha}$. In some cases when the whole set of basic honey plants is used, capacity of pasturages can reach $200-300 \mathrm{~kg} / \mathrm{ha}$. The obtained results show that in Northwest Russia potential forest honey resources allow holding this type of activity in industrial scale. It has been established that vegetation resources of the region are under-studied, and this fact adversely affect development of beekeeping field and its productivity. By contrast, melliferous capacity of pasturages, for example in Vietnam, is significantly higher that is connected with more favorable conditions for bee families and apiary in general. ${ }^{7}$

Research results showed that flowering period of one and the same plant materially vary depending on conditions of a growing area. In open areas flowering of most plants, including honey plants starts earlier than those growing under forest canopy.

Beekeeping is closely connected with crop growing and breeding. Bees are pollinizers of entomophilous plants affecting productivity berry and fruit plants and facilitating renewal of natural flora of forest resources. In addition, special features of climate and vegetation formations must be taken into account. Global warming causes increase in cloud amount of the planet. Number of sunny days tends to reduction that adversely affects summer activity of honey bees and nectar collection.

Early, weak, sustained, continuous by flowering of nectariferous plants honey flow frequently suspended by unfavorable weather conditions is typical for the studied region. Commercialization of the country negatively affected economic status of beekeeping and development of a domestic market of its products. Reduction in number of bee families and production volumes of field products has occurred.

Unavailability of beekeeping regulations results in lack of attention to apiaries using forest areas as a resource base causing considerable losses of products and incomes in budgets of all levels. ${ }^{8-11}$

\section{Acknowledgments}

None.

\section{Conflicts of interest}

Authors declare that there is no conflict of interest.

\section{References}

1. Kositsyn VN. Beekeeping development on forest lands. Forestry. 2009;2:26-28.

2. Samsonova ID. Honey plants of forest and adjacent ecosystems. Forestry. 2008;6:23-24.

3. Sukhanova LV. Forest resources of beekeeping. In: LV Sukhanova, MM Kotov. Forestry. 2000;6:31-32.

4. Griazkin AV. Influence of a method on reliability and accuracy of research results. News of Saint-Petersburg Forestry Academy. St.P.: LTA. 1999;1218.

5. Yaroshevich GS. Scientific justification of beekeeping technology applied in Northwest Russia under conditions of growing technogenic environmental pollution: synopsis of the thesis for the scientific degree of Doctor of Agriculture. 2009:32.

6. Soloviev VV. Special features of making ecologically safe apiculture products under conditions of Novgorod region. Thesis ... Ph.D. of Biology. 2003:18.

7. World Forestry Congress (WFC) side event. Strengthening global part to advance sustainable development of non-wood forest products [electronic resource]. held in Canada on 20 September; 2003.

8. Griazkin AV, Belyaeva NV. Nguyen Thi Thu Ha. Honey plants of leningrad region. Scientific review. 2013;6:18-21.

9. Bogdanova IG. Structure of melliferous conveyor. Forestry. 2010;5:34-36.

10. Rules of forest utilization for farming purposes ..., 2011; Guidelines for record and evaluation of secondary forest resources;2003.

11. Forestry encyclopedia: in 2 volumes. M Vniilm; 2006;424-416. 